\title{
探析小学语文课堂小练笔的教学实践
}

\author{
王欢 \\ 辽宁省盘锦市兴隆台区第一小学 \\ DOI:10.32629/er.v2i3.1701
}

[摘 要] 我国小学语文教育在经历了多年发展后,已经具备了比较完善的教育模式。但受到小学生年龄小这一因素影响,其理 解能力、写作能力自然是不足的,怎样在小学这一重要阶段提高小学生的语文阅读能力、写作能力,为其今后的学业奠定坚实 基础? 一直以来都是小学语文教师致力于解决的问题。而通过随文取材, 找到文章的切入点,进行课堂小练笔的教学实践,是有 利于提高小学生语文素养的。

[关键词] 小学; 语文; 课堂小练笔; 教学实践

对于思想还不成熟、思维不严谨的小学生来说, 写作仍 然是一个比较头疼的问题, 而在长时间的教学实践当中, 我 们发现开展小练笔这种写作训练方式, 易于激发学生的写作 兴趣, 能使其主动拿起笔来写出自己实时所想的话。小练笔 就其表面意思来看, 也就是精悍短小的动手随记, 是发生在 语文课堂教学中的。课堂小练笔的安排得当、落实有效,一 方面是能够使语文课堂变得更轻松、活跃, 另一方面能有效 提高学生的写作能力 ${ }^{[1]}$ 。所以在小学语文实际教学当中, 教 师应准确把握小练笔的时机、策略、切入点, 以此来保证小 练笔落实的有效性。

\section{1 找到教材切入点}

因作文字数要求较多, 在思维上也要有一定的缜密性, 所以导致小学生对写作或多或少都有一定的恐惧心理, 而针 对于此, 教师应在教材当中找到切入点, 使小学生可以有一 个明确的方向来展开写作。

1.1 精彩切入

小学语文教材的选编都是非常严格的, 也都是符合小学 生心智特点的。以《望庐山瀑布》为例, 可以将这种精彩的 古诗作为小练笔的切入点, “飞流直下三千尺、疑是银河落 九天” 这样经典的描写语句能够使学生们感受到瀑布的高 大、宏伟, 使之产生身临其境之感, 基于这一句古诗, 教师可 以以此为切入点开展课堂小练笔, 充分发挥出学生的想象 力。另外像是《小蝌蚪找妈妈》一文当中对小蝌蚪的描写, 也是非常生动的, 以这样精彩的语句描写作为切入点, 指导 学生进行仿写。

\section{2 标点切入}

在很多文章内容当中, 都会通过留白的形式来留给阅读 者一些想象的空间, 这些留白大都是用省略号的方式展现 ${ }^{[2]}$ 。 针对于此, 教师可以选择省略号这一标点作为切入, 使之成为 课堂小练笔的切入点, 例如在《妈妈睡了》这一篇课文当中有 这样的一段描写 “好像在睡梦中, 妈妈又想好了一个故事, 等 会讲给我听……” , 那么这里的省略号中, 妈妈是讲了一个什 么故事呢? 以此为切入, 教师可以让学生去续写省略号中的 内容, 任由其发挥想象力、创造力, 激发活跃的思维, 使其能积
极的投入到课堂教学当中。

另外像是在《三顾茅庐》一文当中在描写刘备走进草堂, 与诸葛亮见面时的情景所写也非常简单, 这也可以让学生联 系整篇内容, 发挥想象, 把诸葛亮与刘备会面的情景写的更 为具体一些。通过这样多次的课堂小练笔, 而反反复复的进 行, 会进一步提高学生的想象力、思维力, 潜移默化的提高学 生的写作能力。

\section{3 略处切入}

为便于表达出文章中的中心内容, 有很多文章当中都会 用到以省略的词语描述正在发生的情境, 而也正是有了这些 词语的存在, 才给阅读者留下很广的想象空间。所以这也是 一个非常好的切入点, 以文章内容当中的省略词做切入, 开 展课堂小练笔, 而通过这样的小练笔, 也有利于学生对文章 的更深刻理解 ${ }^{[3]}$ 。

举例来说, 《荷花》一课当中有这样的一句话: 这么多 的白荷花, 一朵有一朵的姿势, 看看这一朵很美, 看看那一朵 也很美, 在这段话当中, 作者只是概括的去叙述了荷花的美 丽, 其中并没有对荷花的哪一个具体姿态做细嵗的刻画, 因 此这也可以作为课堂小练笔的切入之处, 请学生结合自己在 生活当中看到的荷花, 展开合理、丰富的想象, 去扩充一下荷 花的美丽姿态, 通过想象, 把在原句当中没有写出的内容具 体化, 强化对语言文字的感受力。

再例如在《巨人的花园》一文结尾之处, 文中有这样的 描写: 巨人生活在漂亮的花园和孩子们中间, 感到无比的幸 福。那么, 其中巨人与孩子具体是怎样幸福生活的呢? 又是 怎样玩要的呢? 花园最后是怎样的呢? 这些课文内容均没 有表现, 而这也就恰恰可以作为课堂小练笔的切入点。通过 这样的切入练习, 不仅能提高小学生的想象力、创造力, 而且 也有利于加深他们的课堂思考, 使其对文章有一个更深入的 理解。

1.4 细微切入

在小学语文教材当中, 其中每一篇文章都有很多细节之 处值得我们去深究, 对小学生来说, 他们是很少会关注到的。 因此作为引导者, 小学语文教师应指导学生去关注到那些必 
要关注的细微之处, 使他们通过于此能够培养谨慎、细致的 性格 ${ }^{[4]}$ 。同时, 也可以让学生去仿写这些细微的写作手法, 使 其掌握对细节的描写, 丰富他们的写作方式。

像是《梅花魂》一文, 这篇文章的开头与结尾是相互呼 应的, 在指导学生发现这一细微之处时, 便可以设计课堂小 练笔, 使学生按照这种方法写一段首尾呼应的练笔, 从而掌 握细节描写方法。

\section{2 辅以多样化的写作形式}

小学语文教材选入的文本内容是非常丰富且形式多种 多样的, 这些资源都应被充分利用起来, 和学生实际生活相 连接, 有效开展课堂小练笔。

\section{1 仿写}

儿童模仿才能是天生的, 对于小学生学习作文来说, 仿 写可谓是一种非常重要的途径和训练方法, 能起到对阅读、 写作的桥梁嫁接作用。充分借助于范文来指导学生进行仿写, 能在一定程度上降低写作难度, 保证亦或是激发学生的写作 兴趣, 使其写作能力不断提高, 思维创造能力不断得以发展。

例如一首诗歌《听听, 秋的声音》, 在这首诗歌当中的描 写语言上, 紧抓秋天大自然里的一些声音, 并以诗的优美语 言来赞美了秋天。以此为契机, 让学生去仿写一首诗歌, 采用 形象的描述将各不相同的声音特点体现出来, 而这样学生受 到的启发会更快, 写出: 听听, 秋的声音, 果树晃动身体, 咚咚 是催促收获的号角这一类语言。进行仿写, 一方面是加深了 学生对课文内容的理解程度, 另一方面更是提高了自己的语 言表达能力与写作能力。

\section{2 改写}

改写多是用在对古诗的改写上, 对古诗进行改写, 不仅 能帮助小学生对离其年代较为久远的古诗文内容有更进一 步的理解, 而且也有利于提高学生运用语言的能力 ${ }^{[5]}$ 。小学 语文教材当中选入的古诗大都浅显、易懂, 可以将此作为课 堂小练笔的内容, 基于其对古诗意思的理解, 将这些古诗词 语改写为现代文。

例如在《牧童》这首诗当中, 为了能让小学生真切的感 受到古诗当中牧童的无拘无束和休闲自在境界, 在课堂教学 上, 以牧童为什么 “归来饱饭黄昏后, 不脱萃衣卧月明” 为切 入指导学生展开想象, 那么学生联系之前掌握的学习内容, 有的提出: 牧童在放牛时因为捉蛐蛐把牛丢了, 找牛很累不 愿意脱衣服等等。经过这些的改写, 一片片有趣、自然的文 章自然也就手到擒来了。

以改写的方式来进行课堂小练笔, 不仅能使学生更好的
去理解古诗内容, 更是会让学生跳出古诗, 找到其与其它阅 读内容的相交处, 从而产生在情感上的共鸣, 增加阅读情趣。

\section{3 扩写}

扩写也就是指对原文的扩展、补充, 使文本内容变得更 为具体。扩写方式的应用针对的是课文内容当中留白的部分, 或者是写的含蓄、简练的部分, 这些部分常常会给人留有无 限的遐想空间; 亦或是因为节选的因素, 一些内容被删减掉 了。而小练笔则就紧抓这些留白, 让学生通过课堂小练笔把 这些留白的部分补充具体, 将写的含蓄的地方补充的得以明 朗, 将删减的内容进行补充, 无拘无束, 可以是突破本文限制 的 ${ }^{[6]}$ 。经扩写, 一方面是使学生能更深入的理解课文内容, 另 一方面也是使学生充分发挥其想象力、语言运用能力。

在《再见了, 亲人》这一篇课文当中, 整篇内容皆是志愿 军说的话, 是志愿军战士所追溯的往事, 讲述的是志愿军对 朝鲜人民深厚的情谊。以此作为扩写的课堂小练笔内容: 在 课文当中选择一件志愿军战士为朝鲜人民做的是, 展开想象, 把这件事扩写具体。从而引导学生去更深刻的体会志愿军的 情感, 并想到朝鲜人民对此是怎样想的, 继而认识到志愿军 做出的伟大贡献, 体会到文中所表达出的深厚民族情谊。

\section{3 结语}

小学语文课堂小练笔的教学实践是促进学生读、写共进 的一种有效方式, 能帮助学生更深刻理解课文教材包含的真 正含义, 并理解其中所讲述的道理。而且通过积极的思考、 探索, 会更进一步提高学生对文字的驾驭能力, 提高写作、阅 读能力, 对提示小学生语文素养意义重大。

\section{[参考文献]}

$[1]$ 徐赞.小学语文课堂小练笔教学设计的有效策略 [J]. 作文成功之路(下旬),2016,(4):34。

[2]郭雅琴.论如何实施小学语文阅读教学中课堂小练笔 [J].卷宗,2016,6(12):282.

[3]林海云.浅析小学语文课堂小练笔的教学实践 [J].新 课程上旬,2017,(6):81.

[4]贺勇芬,刘世辉.抓实课堂"小练笔"开启作文成功路一 一以人教版小学三年级语文教材为例 [J]. 基础教育论 坛,2017,(15):25-26.

[5]罗发来.找准切入点让语文课堂小练笔更精彩[J]. 语 文课内外,2018,(27):158.

[6]马燕.课堂小练笔,多样形式提升学生的写作能力 [J]. 新课程上旬,2017,(7):143. 